\title{
Determination of Benzalkonium Chloride in Nasal Drops by High-Performance Liquid Chromatography
}

\author{
DANIJELA A. KOSTIĆ ${ }^{1 *}$, SNEZANA S. MITIĆ ${ }^{1}$, DANIJELA Č. NASKOVIĆ ${ }^{2}$, \\ ALEKSANDRA R. ZARUBICA ${ }^{1}$, AND MILAN N. MITIC ${ }^{1}$
}

\author{
${ }^{1}$ Department of Chemistry, Faculty of Natural Sciences and Mathematics, Visegradska 33, \\ 18000 Niš, Serbia, \\ ${ }^{2}$ D.D. "Zdravlje-Actavis"- Pharmaceutical and Chemical Company, 16000 Leskovac, Serbia \\ *danijelaakostic@yahoo.com
}

Received 14 October 2011; Accepted 20 December 2011

\begin{abstract}
A high-performance liquid chromatography (HPLC) system was used in the reversed phase mode for the determination of benzalkonium chloride (BKC) in nosal drops. A Chromolit RP-18e, 100 x 4.6, (UM6077/035) column was used at $40{ }^{\circ} \mathrm{C}$. The mobile phase, optimized through an experimental design, was a $70: 30 \quad(\mathrm{v} / \mathrm{v})$ mixture of $0.057 \mathrm{M} \mathrm{Na}$ heksansulphonate potassium, dihydrogen orthophosphate buffer $(\mathrm{pH} 2.9)$ and acetonitrile, pumped at a flow rate of $1.75 \mathrm{~mL} / \mathrm{min}$ at maintaining column temperature at $40{ }^{\circ} \mathrm{C}$. Maximum UV detection was achieved at $215 \mathrm{~nm}$. The method was validated in terms of selectivity, linearity, repeatability, precision and accuracy. The method was successfully applied for the determination of BKC in a pharmaceutical formulation of nasal drop solution without any interference from common excipients and drug substance. All the validation parameters were within the acceptance range, concordant to ICH guidelines.
\end{abstract}

Key words: benzalkonijum chloride (BKT), nasal drop, HPLC method

\section{Introduction}

Benzalkonium chloride, also known as alkyldimethylbenzylammonium chloride (ADBAC). It is a mixture of alkylbenzyldimethylammonium chlorides of various even numbered alkyl chain lengths. This product is a nitrogenous cationic surface-acting agent belonging to the quaternary ammonium group. It has three main categories of use; as a biocide, a cationic surfactant and phase transfer agent in the chemical industry. Its applications are extremely wide ranging, from disinfectant formulations to microbial corrosion inhibition in the oilfield sector. It has been considered one of the safest synthetic biocides known and has a long history of efficacious use. Its use as a preservative in cosmetics such as eye and nasal drops attests to its general safety. ${ }^{1}$ 


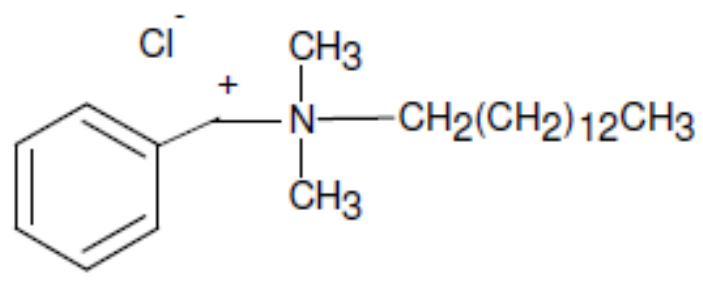

Structure of benzalkonijum chloride (BKC).

A comprehensive literature search revealed that review of preparation, pharmacology, structural relationship, effect with inteded use, HPLC ${ }^{2}$, LC-MS ${ }^{3}$, MS-MS $^{4.5}$ and other chromatographic methods for the determination of BKC were reported. ${ }^{6,7,8}$

However there is lack of a suitable procedure for the quantification and estimation of BKC preservative in nasal drops, where in addition BKC there are other active components such as antibiotics. Therefore, the aim of the presented work is the development and validation ${ }^{9}$ of a simple, precise and accurate method for quantification of benzalkonium chloride (BKC) by HPLC-UV detection, in nasal drops.

\section{Experimental}

\section{Reagents and chemicals}

Benzalkonium chloride with $99.0 \%$ purity was kindly provided from Sigma Aldrich, (Italy). All used solvents were of HPLC grade, while other chemicals were of spectroscopical grade and were obtained from Merck (Darmstadt, Germany). All reagents were used without any further purification. Pharmaceuticals were developed asdrops. All components were obtained from commercial sources and used as received, without any further purification. Pure water was produced by a Millipore Milli-Q Plus System (Molsheim, France).

\section{Stock and Sample Solutions}

$20 \mathrm{mg}$ of benzalkonium chloride (Sigma Aldrich, Milan, Italy) of high purity and known potency was weighed and transferred to a $20 \mathrm{~mL}$ volumetric flask, about $15 \mathrm{~mL}$ of HPLC grade Milli Q water was added and sonicated to dissolve, diluted up to volume with same solvent and mixed. Further $2.0 \mathrm{~mL}$ of this solution was diluted to $10 \mathrm{~mL}$ with mobile phase and mixed $(0.2 \mathrm{mg} / \mathrm{mL})$. The suitability of system and stability of the solution was checked over the period by injecting this solution.

The $1 \mathrm{~mL}$ of nasal drops solution containing $0.01 \%$ BKC (w/v) \& $0.005 \%(\mathrm{w} / \mathrm{v})$ was transferred into a $10 \mathrm{ml}$ volumetric flask and diluted with mobile phase. Solution filtered through the membrane filter pore diameters $0.45 \mu \mathrm{m}$.

\section{Chromatography Conditions}

A The HPLC system consisted of Hewlet Packard HPLC 1100 Series isocratic LC System with DAD (diode array detector) and FLD (flame-photometric detector ) detector.

Column: Chromolit RP-18e, 100 x 4.6, UM6077/035

Mobile phase : $0.05 \mathrm{M} \mathrm{KH}_{2} \mathrm{PO}_{4}+0.057 \mathrm{M} \mathrm{Na}$-heksansulponate : acetonitril (70:130), $\mathrm{pH}$ was adjusted to 2.9 with diluted ortho phosphoric acid, which yields a buffer solution which is 
further used in to preparation of mobile phase. Routine degassing of the mobile phase was carried by passing it through a $0.45 \mu \mathrm{m}$ membrane filter (Millipore, Bedford, MA, USA).

The mobile phase was pumped isocratically at flow rate of $1.75 \mathrm{mLmin}^{-1}$ at $40{ }^{0} \mathrm{C}$. The injection volume was $60 \mu \mathrm{L}$. The UV detection and quantification was done at $215 \mathrm{~nm}$ by injecting $60 \mu \mathrm{L}$ of sample \& standard, with the above chromatographic conditions and after partition equilibration, well shaped peak was eluted.

The composition of the preparations involved:

Operil drops-Lek farmacevtska družba d.d. , Veroškova 57, Ljubljana, Slovenia, The composition of product: oksimetazolin hydrochlorid $\left(0.25 \mathrm{mgml}^{-1}\right)$, BKT $\left(0.055 \mathrm{mgml}^{-}\right.$ $\left.{ }^{1}\right), \mathrm{NaOH}, \mathrm{NaH}_{2} \mathrm{PO}_{4}$, purified water

Olynth drops- McNeil Manufacturing, France

The composition of product: ksilametazolin hydrochlorid $\left(0.5 \mathrm{mgml}^{-1}\right)$, BKT $\left(0.2 \mathrm{mgml}^{-1}\right)$, natrijim-edetat, $\mathrm{Na}_{2} \mathrm{HPO}_{4}, \mathrm{NaH}_{2} \mathrm{PO}_{4}, \mathrm{NaCl}$, sorbitol $70 \%$, purified water

Adrianol drops - Zdravlje Actavis, Leskovac

The composition of product: trimazolin hydrochlorid $(1.5 \mathrm{mg} / \mathrm{ml})$, phenilefrin hydrochloride, BKT $\left(0.2 \mathrm{mgml}^{-1}\right)$, ethanol $96 \%$, glicerol, metilcelulosa M.H.B. $10000, \mathrm{Na}_{2} \mathrm{HPO}_{4}$, citric acid dihydrate, $\mathrm{NH}_{4} \mathrm{Cl}$, purified water

The $1 \mathrm{~mL}$ of nasal drops (Olinth and Adrianol) solution separately was transferred into a 10 $\mathrm{ml}$ volumetric flask and diluted with mobile phase. The 3,64 $\mathrm{ml}$ of nosal drops (Operil) solution was transfered into a $10 \mathrm{ml}$ volumetric flask and diluted with mobile phase. Final concentration of analyzed solutions were $0.02 \mathrm{mgml}^{-1}$.

\section{Method Validation}

The method was validated as per $\mathrm{ICH}^{9}$ guidelines for specificity, linearity, quantification limit, precision, accuracy, recovery and stability. Specificity was investigated by analyzing the blank diluents and samples of $100 \%$ level for any interference of the exciepients at the retention times of BKC. The accuracy of the method was determined by recovery experiments. The precision of the method was demonstrated by interday and intraday variation studies, six repeated injections of standard and sample were made and percentage RSD was calculated. In the intraday variation studies six repeated injections of standard and sample solution was carried out by injecting on the same day at different intervals and percentage RSD was calculated. In the inter day variation studies six repeated injections of standard and sample solution were made for three consecutive days and percentage RSD was calculated. The linearity of the method was demonstrated at seven concentration levels of the mixed standards of BKC.

\section{Result and Discussion}

\section{Specificity/selectivity}

For specificity and selectivity of method, BKC solutions $\left(20 \mu \mathrm{gml}^{-1}\right)$ were prepared in the mobile phase along with and without common excipients, separately. All the solutions were injected into the Chromolit RP-18e, 100 x 4.6 column. In this assay, it was tested by running solutions containing the placebo of the specialties in the same quantities and in the conditions in which the samples to show that there is no peak in the retention times corresponding to the analytes. The retention time of BKC was determined as $2 \mathrm{~min}$. No peaks interfered with the detection of BKC in the samples (Figure 1.), indicating that the HPLC method is effective. For calculating concentration of BKT the surface of peak witch retention time is $2 \mathrm{~min}$, was used. 


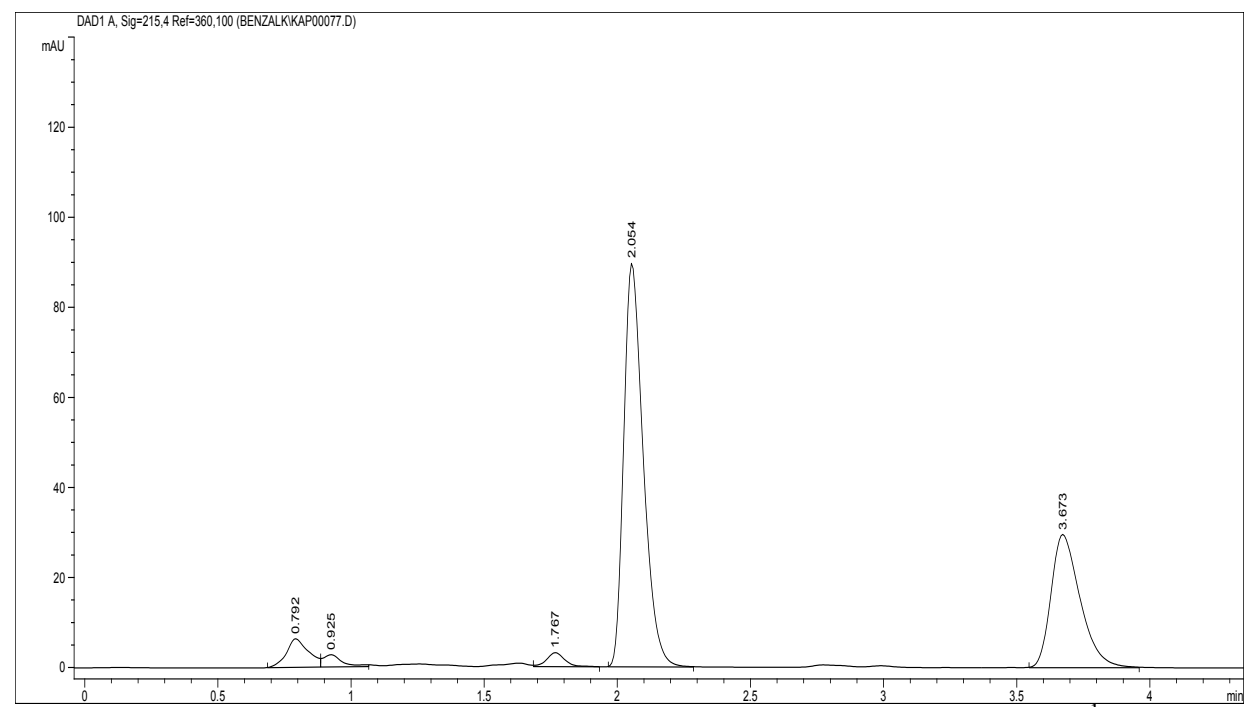

Figure 1. Representative chromatograms of BKC standard solution $\left(20 \mu \mathrm{gml}^{-1}\right)$ Linearity.

The linearity was checked on samples of standard BKT at five different concentrations (16$24 \mu \mathrm{gml}^{-1}$ ). A standard curve according to the ratio peaks of BKT versus peaks for BKT concentrations was constructed, and presented by linear equation :

$\mathrm{y}_{215}=23520 \mathrm{x}-11.9, \mathrm{R}^{2}=0.9981$.

where $x$ represents concentration in $\mu \mathrm{g} \mathrm{ml}^{-1}, y$ represents the HPLC peak area, which was automatically measured by an integrator of the HPLC instrument, and $R$ is the correlation coefficient.

The calculations were performed on a personal computer using the Microsoft Excel program (Version 2003, Microsoft Co., Redmond, USA, 2003). Least-squares regression analysis was used to evaluate the concentration range data that showed excellent linearity over the interval studied, with $\mathrm{R}^{2} \geq 0.99$.

\section{Accuracy}

The accuracy of the method was checked by determining recovery values. Series of solution were made containing 80,100 and $120 \%$ of BKC regarding the declared content. The results are presented in Table 1.

Table 1. Accuracy data for the developed method $(n=6)$.

\begin{tabular}{|c|c|c|c|}
\hline Added value $\mu \mathrm{gml}^{-1}$ & $\begin{array}{c}\text { Measured value } \\
(\mathrm{mg} / \mathrm{ml})\end{array}$ & $\begin{array}{c}\text { Relative recovery } \\
(\%)\end{array}$ & RSD (\%) \\
\hline 16.00 & $15.12 \pm 0.30$ & 94.45 & 0.317 \\
\hline 20.00 & $20.17 \pm 1.10$ & 100.86 & 1.092 \\
\hline 24.00 & $23.15 \pm 0.80$ & 96.44 & 0.838 \\
\hline
\end{tabular}

The results were found within the acceptance criteria with acceptable \% RSD of within $2.0 \%$ at each level. The recovery at each level were between 98.0 to $102.0 \%$ which indicated that 
the method is appropriate to produce accurate estimation of BKC preservative analogue in said formulation.

\section{Limit of detection and quantification}

The limit of detection $(L O D)$ and quantification $(L O Q)$ were calculated according to the following formula:

$L O D=3 S_{\mathrm{do}} / b_{\mathrm{sr}}=4.23 \mu \mathrm{g} \mathrm{ml}^{-1}$

$L O Q=10 S_{\mathrm{do}} / b_{\mathrm{sr}}=13.3 \mu \mathrm{g} \mathrm{ml}^{-1}$

where $S_{\mathrm{do}}$ is the standard deviation of the response and $b_{\mathrm{sr}}$ is the mean value of the slope of the calibration curve constructed during the linearity determination.

\section{Precision}

The precision was determined by measuring six sample probes under the same experimental conditions. The obtained results are given in Table 2, together with the calculated values of their standard deviation, SD, and relative standard deviation, RSD.

Table 2: Precision of the method.

\begin{tabular}{|l|l|l|l|l|}
\hline $\mathrm{BKC}\left(\mu \mathrm{gml}^{-1}\right)$ & $\mathrm{N}$ & $\mathrm{X}_{\mathrm{sr}}$ & $\mathrm{S}_{\mathrm{d}}$ & $\mathrm{RS}_{\mathrm{d}}(\%)$ \\
\hline 19.55 & 6 & 19.61 & 0.21 & 1.07 \\
\hline 19.75 & & & & \\
\hline 19.28 & & & & \\
\hline 19.64 & & & & \\
\hline 19.57 & & & & \\
\hline 19.89 & & & & \\
\hline
\end{tabular}

The method is precise since $R S D<R S D_{\max } . R S D_{\max }$ is $2 \%$, which represents the maximum allowed value of the $R S D$ for HPLC methods according to the Pharmacopoeias.

Application of the developed method to determination of BKC in nosal drops.

The outcome of the application of the developed method to the determination of BKC in some nosal drops are shown in Figures 2.

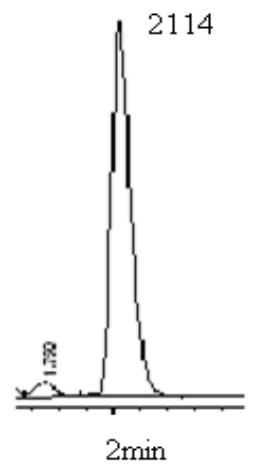

a)

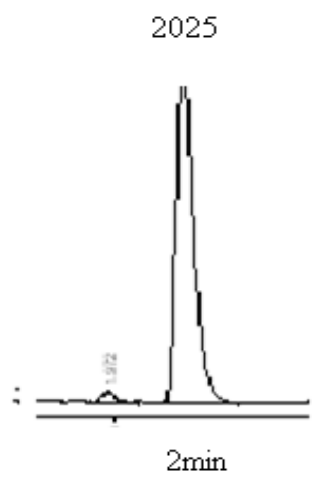

b)

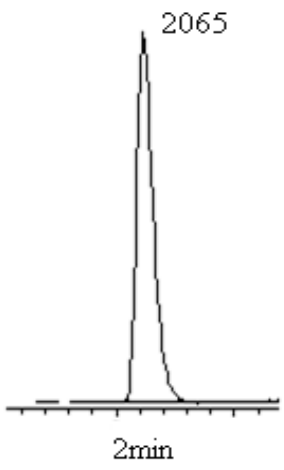

c)

Figure 2. Representative chromatograms of working solution $\left(\mathrm{c}_{\mathrm{BKC}}=20 \mu \mathrm{gml}^{-1}\right)$, a) Olinth drops , b) Operil drops, c) Adrianol drops. 
The representative chromatograms of the standard sample of BKC and in the investigated nasal solution show identical retention times. Assay results for the determination of BKC in commercial nasal drops are shown in Table 3.

Table 3: Assay results for the determination of $\mathrm{BKC}$ in commercial nasal drops.

\begin{tabular}{llll}
\hline Preparation & taken & found & RSD (\%) \\
& BKC $\left(\mu \mathrm{gml}^{-1}\right)$ & BKC $\pm \mathrm{SD}\left(\mu \mathrm{gml}^{-1}\right)$ & \\
\hline Operil drops & 20 & $19.55 \pm 0.23$ & 1.17 \\
Olynth drops & 20 & $20.38 \pm 0.07$ & 0.35 \\
Adrianol drops & 20 & $19.80 \pm 0.12$ & 0.60 \\
\hline
\end{tabular}

RSD (\%) is accuracy of determination BKC in investigated pharmaceutical preparation. The results obtained were compared with those given by a reference method. ${ }^{10}$

\section{Conclusion}

The proposed RP-HPLC method is simple, sensitive, rapid and specific and can be used for in a drug manufacturing quality control of BKT in nasal drops formulations. The method described in this study was suitable to determine concentrations in the range 16-24 $\mu \mathrm{gml}^{-1}$ for BKT, precisely and accurately. Limits of detection and quantization for BKT with lower

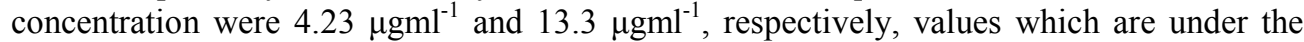
lowest expected concentrations in the sample. The sample recovery from the formulation was in good agreement with its respective label claim, which suggested non-interference of formulation excipients in the estimation.

\section{References}

1. http://en.wikipedia.org/wiki/Quaternary_ammonium_compound.

2. Parhizkari G, Delker R, Miller B and Chen C Chromatogr., 1985, 40, 155

3. Gomez-Gomar A, Gonzalez-Aubert M M, Garces-Torrents J and Costa-Segarra J J.

4. Pharmaceut. Biomed. Anal., 1990, 8, 871

5. Hou Y H, Wu C Yand Ding WH, J Chromatogr. A, 2002, 976, 207.

6. Labranche LP, Dumont S N, Levesque S and Carrier A J .Pharmaceut. Biomed. Anal.,

7. 2007,43, 989.

8. Dudkiewicz-Wilczyska J, Tautt J and Roman I J . Pharmaceut. Biomed. Anal., 2004, 34, 909.

9. Kümmerer K, Eitel A, Braun U, Hubner P, Daschner F, Mascart G, Milandri M, Reinthaler F and Verhoef J, J. Chromatogr. A, 1997, 774, 281

10. Elrod L Jr,. Golic T G and Morley J A, J Chromatogr. A, 1992,625, 362

11. ICH, Validation of Analytical Procedure: Methodology, ICH Harmonised Tripartite Guidelines, Adopted, November 6, 1996.

12. Abdel Kader AM, Taha AM and Abdel Fattah S Pharmazie, 1980,35, 30 


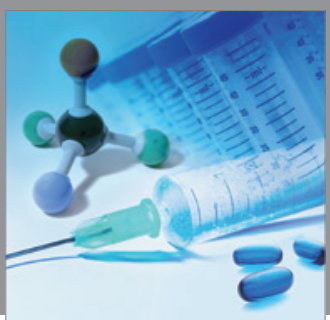

International Journal of

Medicinal Chemistry

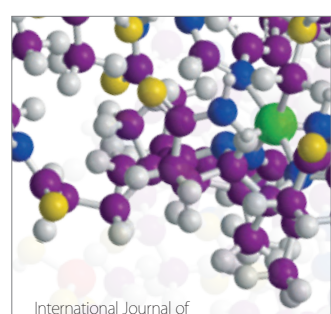

Carbohydrate Chemistry

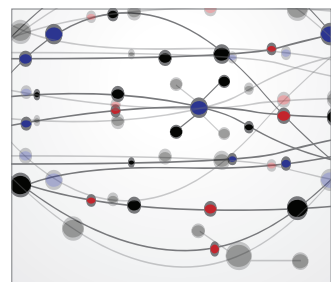

The Scientific World Journal
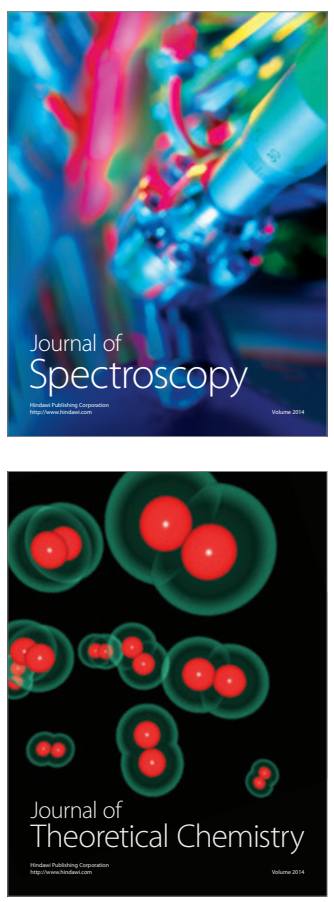
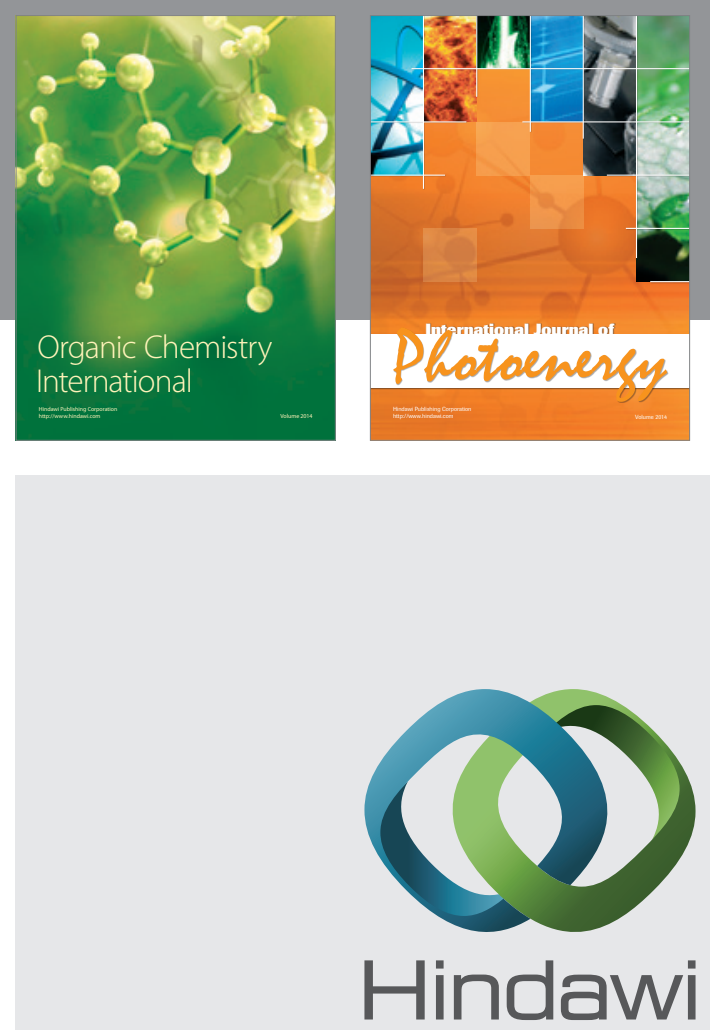

Submit your manuscripts at

http://www.hindawi.com
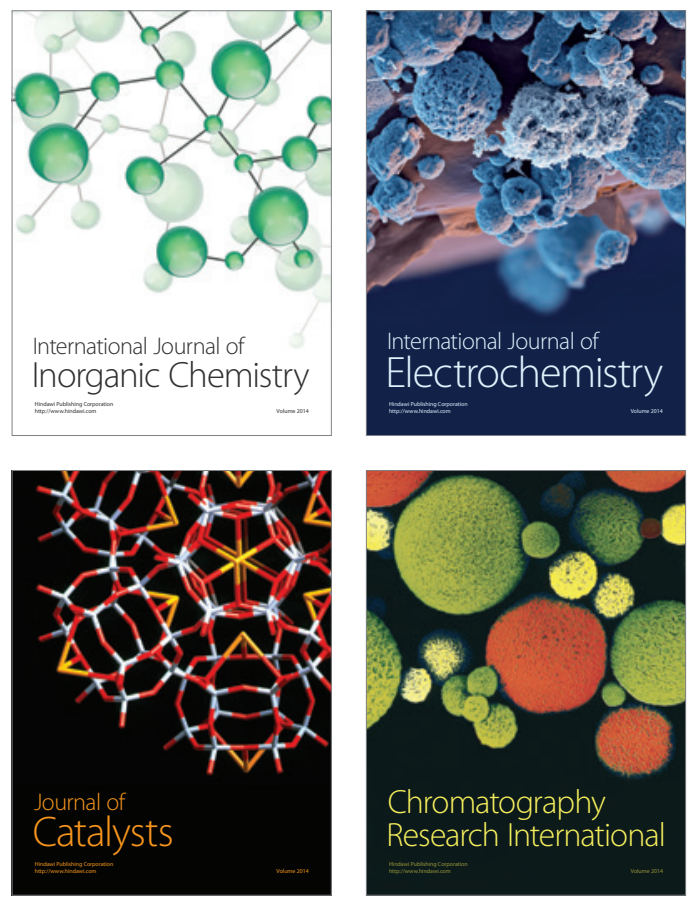
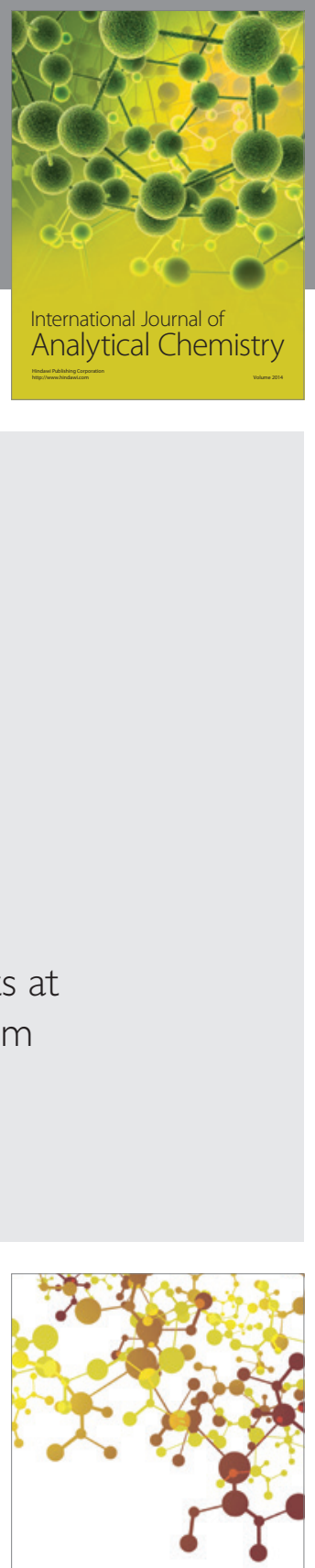

Journal of

Applied Chemistry
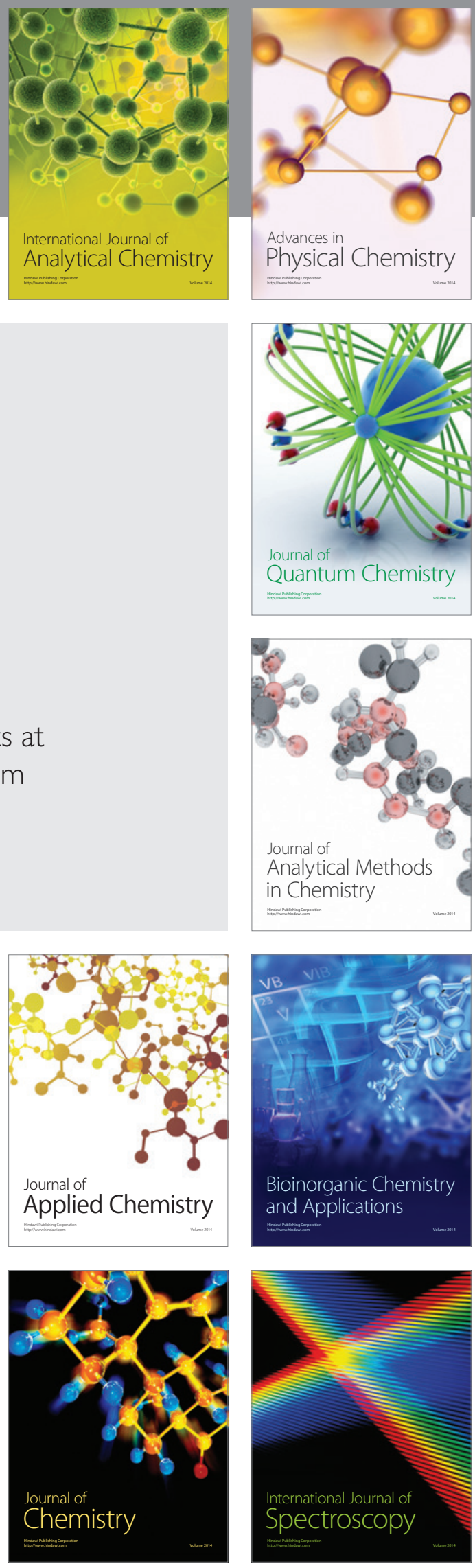